\title{
Comparison of Microvessel Density Using Nestin and CD34 in Colorectal Cancer
}

\author{
MARIUSZ CHABOWSKI ${ }^{1,2}$, ALEKSANDRA NOWAK ${ }^{3}$, JEDRZEJ GRZEGRZOLKA ${ }^{3}$, \\ ALEKSANDRA PIOTROWSKA ${ }^{3}$, DARIUSZ JANCZAK ${ }^{1,2}$ and PIOTR DZIEGIEL ${ }^{3}$ \\ ${ }^{1}$ Division of Surgical Specialties, Department of Clinical Nursing, Faculty of Health Science, and \\ ${ }^{2}$ Department of Surgery, 4th Military Teaching Hospital, Wroclaw, Poland; \\ Wroclaw Medical University, Wroclaw, Poland; \\ ${ }^{3}$ Division of Histology and Embryology, Department of Human Morphology and Embryology, \\ Wroclaw Medical University, Wroclaw, Poland
}

\begin{abstract}
Background/Aim: The aim of the present study was to compare the prognostic value of nestin-positive microvessel density (nestin + MVD) to the CD34-positive (CD34+) MVD in patients with colorectal cancer. Materials and Methods: A total of 125 cases of colorectal cancer were used for the study. Immunohistochemical reactions were performed on paraffin sections using anti-nestin and antiCD34. The average MVD was determined for both markers and was referenced to patients' clinicopathological data. Results: A strong positive correlation was found between the MVDs for both analyzed antigens. Contrary to CD34+ MVD, a positive trend was observed between high nestin+ MVD and lymph node invasion. Moreover, significantly higher nestin+ MVD was noted in patients with more advanced clinical stage than in those with early-stage cancer. No such correlation was found for CD34 antigen. Additionally, a possible trend between the higher nestin+ $M V D$ and shorter event-free survival was noted, whereas no such relation was observed for CD34+ MVD. Conclusion: The results suggest that nestin might be a reliable marker for angiogenesis evaluation in patients with colorectal cancer. In contrast to CD34, the expression of nestin in blood vessels seems to be a more sensitive marker of cancer progression.
\end{abstract}

Colorectal cancer (CRC) is the third most commonly diagnosed cancer worldwide in men and the second in women. In 2012, the total number of colorectal cancer

Correspondence to: Mariusz Chabowski, MD, Ph.D., Dept. of Surgery, 4th Military Teaching Hospital, 5 Weigla street, 50-981 Wroclaw, Poland. Tel: +48261 660247, Fax: +48 261660245, e-mail: mariusz.chabowski@gmail.com

Key Words: Nestin, CD34, colorectal cancer, microvessel density, survival. patients reached 1.4 million (1). It is estimated that in 2017, the number of newly diagnosed CRC was 135,430 , while the number of CRC-related deaths was 50,260 cases per year in the United States alone (2). CRC, together with lung and genital carcinomas, is the leading cause of death for both men and women (3). According to the report of the World Health Organization "Global Burden of Disease", the number of CRC-caused deaths increased from 327,000 in 1990 to 832,000 in 2015 , which represents an increase of $57.4 \%$ (4).

About $95 \%$ of cases of colon cancer originate from the epithelium of the large intestine mucosa, thus being classified as adenocarcinomas. Other histological types, such as carcinoids originating from endocrine-active cells, gastrointestinal stromal tumours (GIST) originating from precursors of Cajal cells, and sarcomas arising from mesenchymal elements of the intestinal wall, are identified much less frequently (5).

CRC is characterized by a lack of specific symptoms at the onset of the disease, which results in late diagnosis (6). Introduction of screening tests improves early CRC detection, however, these are not effective enough in the ageing populations of highly developed countries (1). Another aspect is the high mortality of CRC and a still insufficient number of specific biomarkers that allow precise evaluation of CRC progression and treatment response. Great hopes are being pinned on the evaluation of tumour microvessel density (MVD), which reflects angiogenesis and directly correlates with the clinical characteristics of the cancerous process. Since the administration of anti-angiogenic treatment is effective in patients with CRC, it seems reasonable to search for new prognostic markers which enable the evaluation of such treatment. Currently, the most commonly used angiogenesis markers are vascular endothelial antigens, such as CD31 and CD34. However, these antigens are not specific for newly-forming tumour vessels because they are also expressed by mature vessels (7). 
CD34 is a transmembrane glycoprotein that belongs to the family of adhesion molecules - sialomucins. Initially, CD34 was considered a marker of haematopoietic stem cells; subsequently, its presence was also shown on other stem/progenitor cell types (8-10), including vascular endothelium progenitor cells (11). CD34 is involved in adhesion-related processes, as well as in the regulation of cell proliferation and differentiation (12). The expression of CD34 in blood vessels reflects their progenitor nature, which has allowed for its application in the evaluation of angiogenesis in many cancer types (13-16).

Nestin, a protein of the intermediate filaments of the cytoskeleton, appears to be more specific marker for newly formed blood vessels (17-19). Initially, nestin expression was reported in neuroepithelial stem cells, but further studies revealed its presence in many other progenitor cells i.e. vascular endothelial cells (20-23). Reports in the literature shows that nestin is a reliable marker of newly formed tumour vessels, which also has potential clinical implications (24). A higher nestin-positive microvessel density (MVD) is associated with more aggressive cancer progression and poorer prognosis $(18,19)$.

The aim of this work was to evaluate the average density of nestin-expressing microvessels in CRC in comparison with those expressing CD34. The correlation between the expression of both antigens and selected clinicopathological data was also analysed. The prognostic value of nestin and CD34 were analyzed by determining their correlation with overall survival (OS), as well as event-free survival (EFS). Moreover, nestin was evaluated as a marker of cancer progression by determining its correlation with lymph node metastasis and the clinical stage of the disease.

\section{Materials and Methods}

A total of 125 patients operated on due to CRC at the Fourth Military Clinical Hospital in Wroclaw, Poland, were included in the study. The median age of patients was $69.8 \pm 10.3$ years. Patients were operated on between July 2012 and October 2016. The median follow-up period was 49.8 months. $29(23.2 \%)$ patients died during the follow-up period.

During the surgeries, tissue samples were taken for histopathological evaluation. Adenocarcinoma was identified in 123 patients. In the remaining two cases, medullary and planoepithelial carcinoma were diagnosed. Clinical characterisation of the study group and the type of treatment are shown in Table I.

The study was conducted with the consent of Ethics Committee of Wroclaw Medical University (no. KB 29/2011). Patients gave written consent to participate in the study.

Tissue microarrays (TMAs) and immunohistochemistry (IHC). The cancer samples were derived from formalin-fixed paraffin embedded tissue blocks with primary CRC specimens. Firstly, haematoxylin and eosin $(\mathrm{H} \& \mathrm{E})$ slides corresponding to each tissue block were scanned (The Pannoramic MIDI; 3D Histech, Budapest, Hungary) and three areas of colonic adenocarcinoma from each sample were circled by two pathologists. TMA blocks were constructed with a
Table I. Clinical characterisation of the study group and type of treatment.

\begin{tabular}{lcc}
\hline Characterisation of patients & $\mathrm{N}$ & $\%$ \\
\hline Lymph node metastases & & \\
Yes & 47 & 37.6 \\
No & 78 & 62.4 \\
Clinical stage & 23 & \\
I & 42 & 18.4 \\
IIA & 1 & 33.4 \\
IIB & 5 & 0.8 \\
IIIA & 31 & 4 \\
IIIB & 2 & 24.8 \\
IIIC & 21 & 1.6 \\
IV & 123 & \\
Muscle infiltration & 2 & 98.4 \\
Yes & & 1.6 \\
No & 94 & 75.2 \\
Subserosal infiltration & 31 & 24.8 \\
Yes & & \\
No & 2 & 1.6 \\
Neoadjuvant chemotherapy & 123 & 98.4 \\
Yes & & \\
No & 61 & 48.8 \\
Adjuvant chemotherapy & 64 & 51.2 \\
Yes & 12 & 9.6 \\
No & 113 & 90.4 \\
Radiotherapy & & \\
Yes & & \\
No & & \\
\hline
\end{tabular}

computer-controlled TMA Grand Master tissue microarrayer (3D Histech). Three tissue cores of $1.5 \mathrm{~mm}$ diameter were extracted from the circled areas in each donor block and automatically transferred to a recipient TMA block. The study required a series of five TMA blocks (containing samples from 125 patients), from which $4-\mu \mathrm{m}$ sections were cut and immunostained using an Autostainer Link48 (Dako, Glostrup, Denmark). The sections were boiled in EnVision FLEX Target Retrieval Solution ( $\mathrm{pH} 9.0$, at $97^{\circ} \mathrm{C}$ for $20 \mathrm{~min}$ ) using Pre-Treatment Link Platform (both from Dako). Activity of endogenous peroxidase was blocked by $5 \mathrm{~min}$ incubation with EnVision FLEX Peroxidase-Blocking Reagent (Dako). The samples were incubated with primary antibodies against nestin $(1: 100$ dilution, OBT1610; Bio-Rad, Hercules, CA, USA) and CD34 (readyto-use, IR632; Dako) for $20 \mathrm{~min}$ at room temperature (RT) and then incubated with EnVision FLEX/HRP for $20 \mathrm{~min}$ (Dako). The sections were then incubated for $10 \mathrm{~min}$ with 3.3'-diaminobenzidine (DAB; Dako) as the peroxidase substrate. All slides were counterstained with EnVision FLEX Hematoxylin (Dako) for 5 min and closed with coverslips in Dako Mounting Medium (Dako).

Evaluation of IHC reactions. Immunostained TMA spots were analysed and scored following full-slide digitalization with the Pannoramic Scan and the database-linked TMA Modul software (both 3D Histech). From 125 samples on slides, 11 were excluded from analysis due to limited amount or poor quality of the material. In order to evaluate MVD, all immunolabelled vessels were counted 

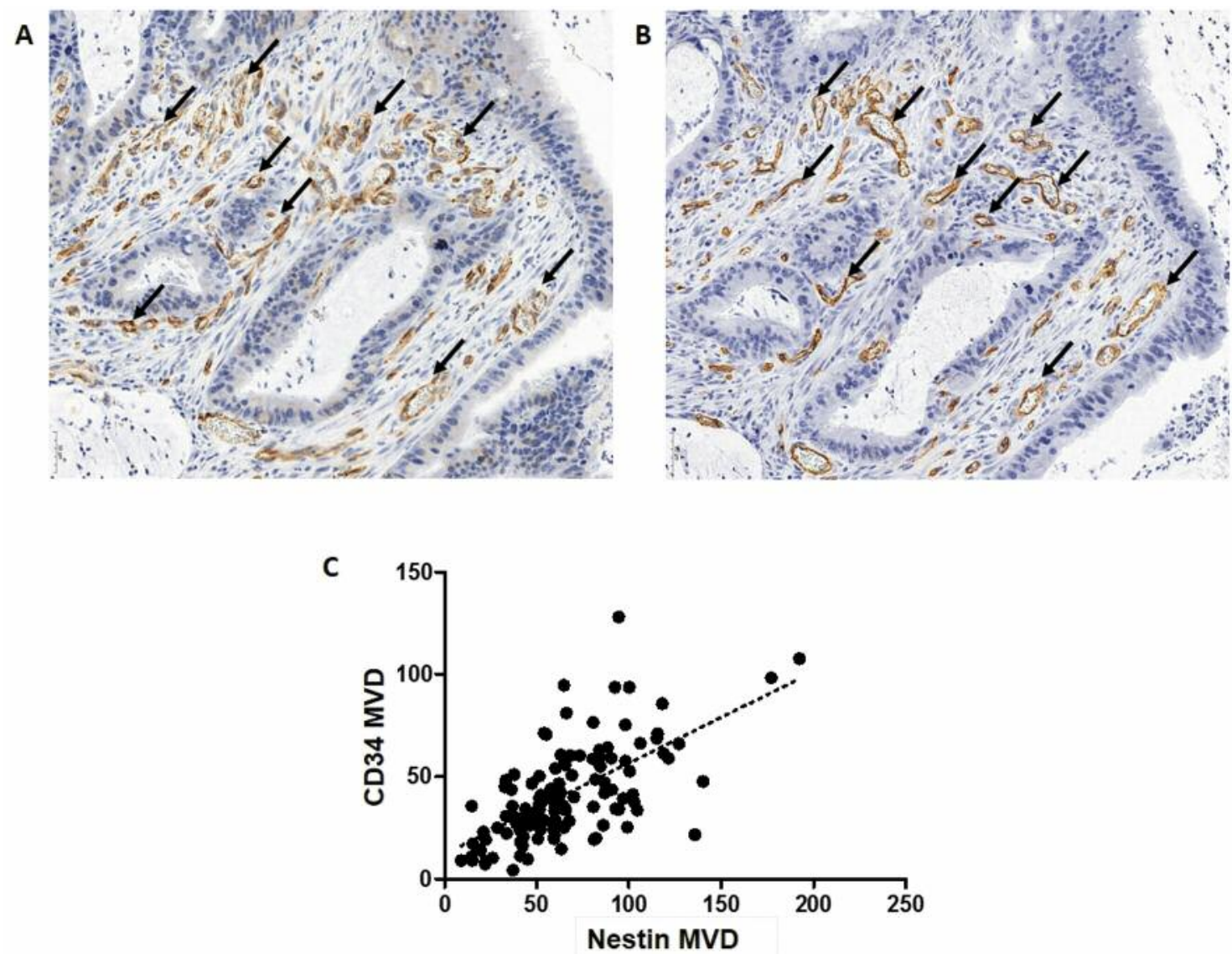

Figure 1. Immunohistochemical expression of nestin (A; black arrows, $\times 220)$ and CD34 (B; black arrows, $\times 220)$ in tumour vessels of colorectal carcinoma (serial sections). Microvessel density (MVD) by nestin positively correlated with that by CD34 $(C ; r=0.63, p<0.0001 ;$ Spearman rank correlation test).

in three tissue spots for each antigen. Finally, MVD was recorded as the mean number of vessels from the three tissue spots. Any stained endothelial cell or endothelial cell clusters were counted as a single microvessel, even in the absence of vessel lumen $(25,26)$.

Statistical analysis. All statistical analyses were performed using Prism 5.0 (GraphPad, La Jolla, CA, USA) and Statistica 10 (StatSoft Inc., Tulsa, OK, USA). The Kolmogorov-Smirnov test was applied to determine whether sample data were normally distributed. The Mann-Whitney test was used to compare the groups of data that did not meet the assumptions of the parametric test. The Spearman correlation test was used to analyse the existing correlations. The Kaplan-Meier method and the Mantel-Cox test were used to determine the significance of patient OS and EFS. The survival times were measured from the start of the treatment. Differences were considered statistically significant at $p<0.05$.

\section{Results}

The average MVD by nestin expression was determined in 114 out of 125 patients with CRC (Figure 1A). The density of CD34-expressing blood vessels was evaluated in 121
Table II. Characterisation of microvessel density by nestin and CD34 in biopsies from the study group of patients with colon cancer.

\begin{tabular}{lccccc}
\hline $\begin{array}{l}\text { Microvessel } \\
\text { density }\end{array}$ & $\mathrm{n}$ & Mean \pm SD & Median & Range & $\begin{array}{c}\text { Interquartile } \\
\text { range }\end{array}$ \\
\hline Nestin & 114 & $41.65 \pm 23.23$ & 36.83 & $4.33-128.00$ & $24.83-55.75$ \\
CD34 & 121 & $64.69 \pm 33.07$ & 60.00 & $6.00-192.30$ & $41.92-85.17$ \\
\hline
\end{tabular}

patients (Figure 1B). Statistical data on MVD determined using nestin and CD34 markers are shown in Table II.

A fairly strong positive correlation was found between the MVDs determined for both markers $(\mathrm{R}=0.63, p<0.0001)$ (Figure 1C). The comparison of MVD in patients without regional lymph node metastasis (N0) and in patients with tumour cells identified in at least one lymph node (N1-3) showed a positive trend between nestin+ MVD and the presence of lymph node metastases (Figure 2A). On the 
A
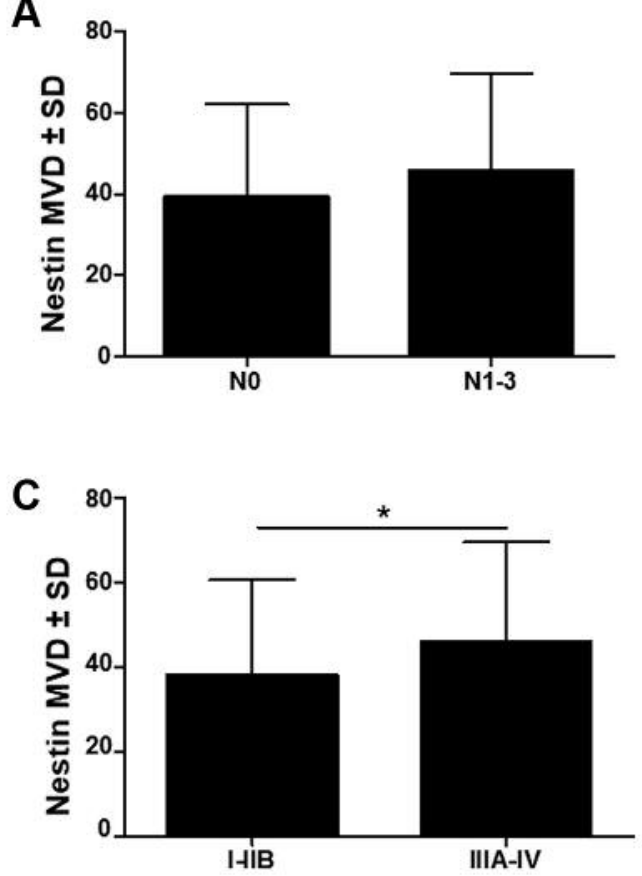

B

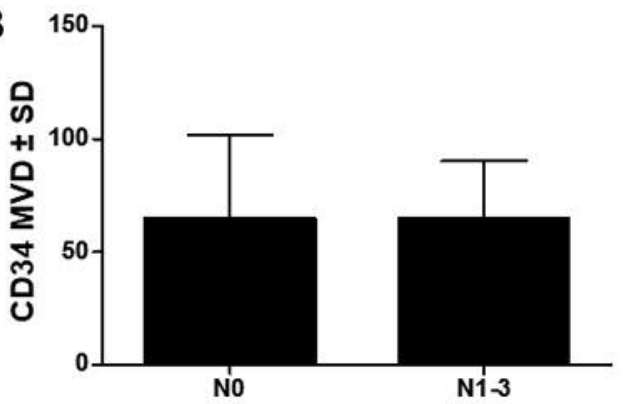

D

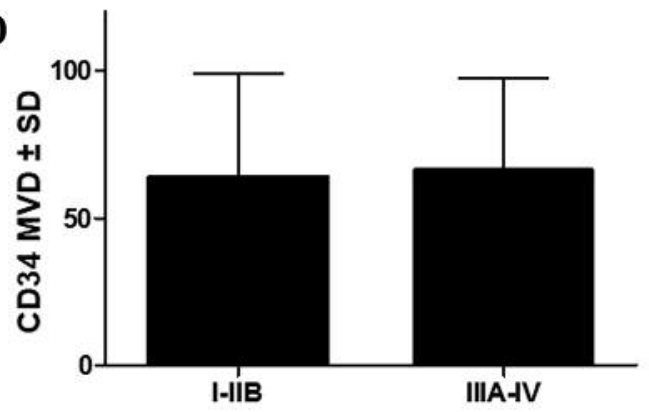

Figure 2. Comparison of microvessel density $(M V D)$ by nestin $(A, C)$ and $C D 34(B, D)$ according to lymph node metastasis $(A, B)$ and disease stage $(C, D) . M V D$ by nestin was marginally higher in patients with lymph node metastasis ( $p=0.0718$ ) but did not differ for MVD by CD34. MVD by nestin was significantly higher in patients with an advanced stage of the disease (C; *p=0.0304; Mann-Whitney test), whereas for CD34 MVD, no significant association with disease stage was observed ( $D ; p=0.4822 ;$ Man-Whitney test).

contrary, in case of the CD34+ MVD, no association with lymph node status was observed. (Figure 2B). Moreover, in patients with early clinical stage (I-IIB), nestin+ MVD was significantly lower than in patients with advanced stage (IIIA-IV) cancer ( $p=0.03$, Figure $2 \mathrm{C}$ ). On the other hand, the comparison of the values of CD34+ MVD between those groups did not show any significant difference $(p=0.4822$, Figure 2D).

The difference in OS between patients classified into high and low MVD groups according to the median MVD values was not statistically significant for nestin nor CD34 ( $p=0.5406$ and $p=0.2365$, respectively) (Figure 3A and B). Nonetheless, a positive trend was noted between higher nestin+ MVD and shorter EFS in patients with CRC patients. (Figure 3C and D).

\section{Discussion}

In the current study, significant positive correlation was shown between nestin and CD34, a marker which is commonly used for the evaluation of MVD in CRC tissue samples. The results suggest that nestin might be a more reliable marker for angiogenesis evaluation in patients with CRC than CD34. In comparison to CD34, nestin was also shown to be a more sensitive indicator of CRC progression. Additionally, nestin showed a positive trend for EFS prediction in patients with CRC, whereas no such relation was observed for CD34.

The correlation between new blood vessel formation and the cancerous process was observed for the first time in 1945. Algire et al. showed that transplanted cancer cells were able to induce vessel formation before the tumour reached a significant size. The authors suggested that the formation of new blood vessels is necessary for the growth of neoplastic tumours (27). However, a breakthrough was the study conducted by J. Folkman, who showed that a tumour cannot grow without the development of its own network of blood vessels $(28,29)$. A number of later studies confirmed this thesis and showed that rapid cancer growth and metastasis are associated with angiogenesis. A higher density of blood and lymph vessels within a tumour increases the probability of vessel infiltration, and therefore favours cancer cell spread and distant metastasis (30). The outcome of a meta-analysis conducted by Wang et al. on the collective analysis of results from 18 studies confirmed the prognostic value of MVD in patients with CRC. Despite that, the interpretation of those results is limited (31). The authors of the meta-analysis underline that the analysis included a heterogeneous group 

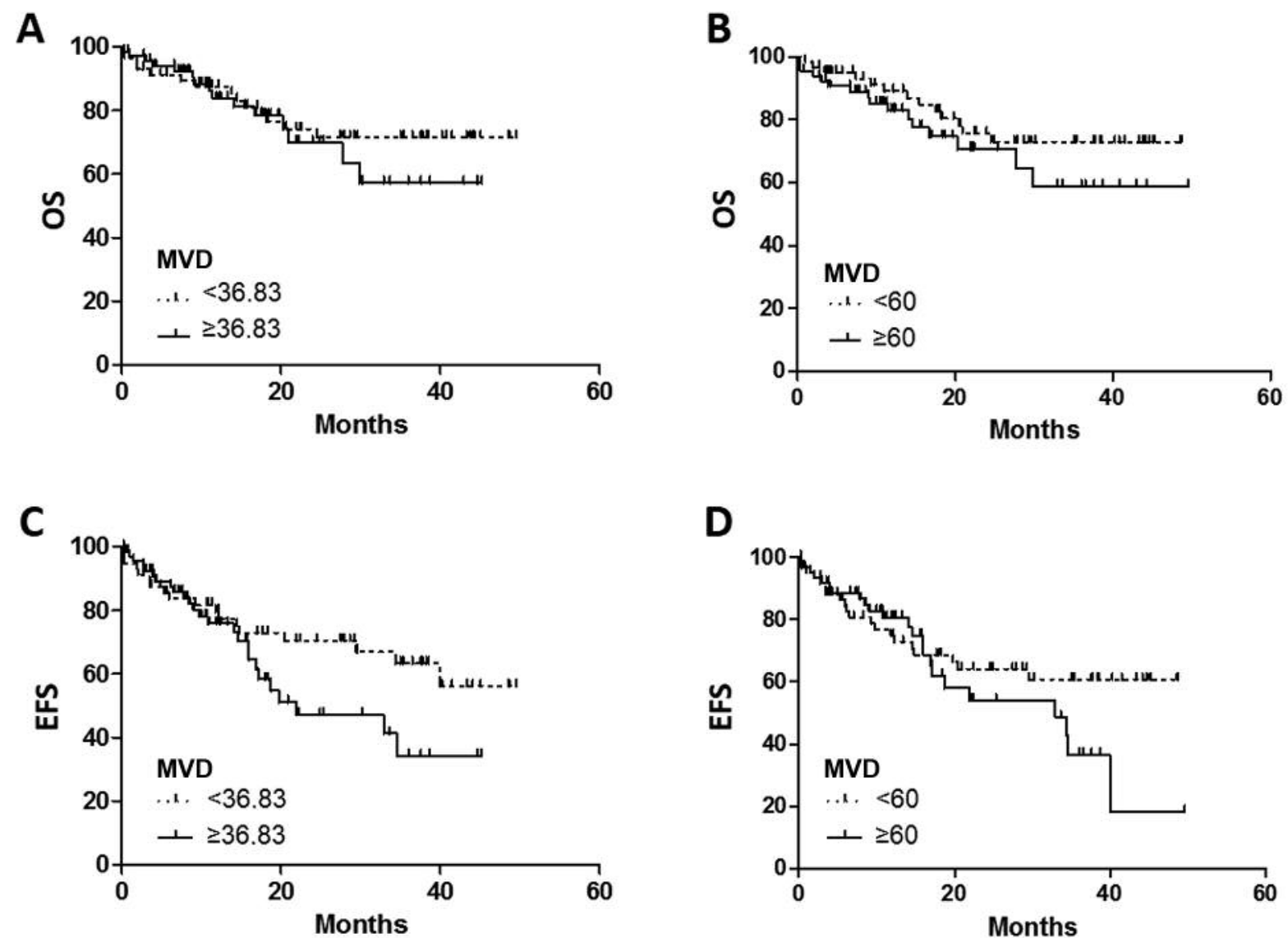

Figure 3. Analysis of overall survivaI $(O S)(A, B)$ and event-free survival $(E F S)(C, D)$ for microvessel density $(M V D)$ by nestin $(A, C)$ and $C D 34$ $(B, D)$. Median values of nestin (36.83) and CD34 (60) were used as cut-offs in order to divide patients into groups with high and low MVD. Neither nestin ( $p=0.5406$; Mantel-Cox) nor the CD34 ( $p=0.2365$; Mantel-Cox) were related to OS in colorectal cancer. Findings were similar for EFS (nestin, $p=0.0983 ; C D 34, p=0.2803 ;$ Mantel-Cox). However, a trend towards significance was observed for the association between high nestin+ MVD and shorter EFS of patients ( $p=0.0983$ ).

of patients whose MVD was evaluated with different methods using more or less sensitive markers. Some CD31and CD34-based studies did not confirm prognostic value of these two antigens (32-34). However, in other studies, MVD estimated with the use of these markers was correlated with cancer recurrence and shorter survival (34-37). As there are no unambiguous results, there is a need to search for more sensitive markers for the evaluation of angiogenesis in CRC. Taking into account the results of previous studies $(18,19)$, we suggest nestin as a new biomarker for angiogenesis assessment in patients with CRC.

Nestin plays an important role in cellular cytoskeleton organisation and in organogenesis. Its presence on vascular endothelial progenitor cells in cancerous tissue enables the identification of newly-formed blood vessels during intense angiogenesis. Nestin was found to be present in the cytoplasm of most vascular endothelial cells in gastric and colon cancer $(17,37)$. Characteristically, increased immunoreactivity for nestin on the interface between the tumour boundary and surrounding tissues is also observed $(17,37)$. Kim et al. showed a significantly stronger colour reaction in tumour vessels with anti-nestin than with antiCD34, wherein both results were strongly correlated (17). Similar results were obtained in our study by the comparison of MVD measurement for nestin and CD34. We also showed significant correlation between the expression of both markers in vascular endothelial cells.

Strong correlation between the expression of proliferating cell nuclear antigen and nestin expression in vascular endothelium indicates that nestin could potentially be used for the identification of newly formed, proliferating vessels (38). There was no such correlation observed for CD34 antigen (38). Nestin gene knockdown in endothelial cells inhibited blood vessel formation and cancer progression $(39,40)$. These reports confirm that nestin might be a significantly better marker of angiogenesis in comparison to CD34. 
MVD was shown to be an important prognostic factor in several previous studies $(18,41,42)$. Nevertheless, the most important information is the density of newly formed vessels, as they have a relatively permeable and thin basement membrane, which enables bloodstream penetration by cancer cells and the spread of cancer. Penetration of mature blood vessel walls by cancer cells is much more difficult (38). Significant positive correlation between the density of nestin-expressing vessels and liver metastasis in CRC indicates that a tumour's potential for growth, infiltration and metastasis depends on angiogenesis and rapid development of new blood vessels, both in the tumour centre and in the invasive front $(43,44)$. Some reports showed that the density of nestin-expressing vessels within tumour reflects patient survival. Teranishi et al. showed that EFS was significantly shorter in patients with high MVD by nestin. No prognostic value was shown for CD34 marker in the same patients (38). The results of our study are consistent with those findings. In our study, nestin+ MVD showed a positive trend for predicting disease recurrence in patients with CRC, whereas CD34+ MVD showed no such value. Several other reports also confirmed that evaluation of nestin expression in tumour cells is an important prognostic marker in other cancer types $(18,45-47)$. Taking into account all the above data, in the future, nestin may be confirmed as a better marker of angiogenesis in CRC than CD34.

\section{References}

1 Torre LA, Bray F, Siegel RL, Ferlay J, Lortet-Tieulent J and Jemal A: Global cancer statistics, 2012. CA Cancer J Clin 65(2): 87-108, 2015.

2 Siegel RL, Miller KD, Fedewa SA, Ahnen DJ, Meester RGS, Barzi A and Jemal A: Colorectal cancer statistics, 2017. CA Cancer J Clin 67(3): 177-193, 2017.

3 Siegel RL, Miller KD and Jemal A: Cancer statistics, 2018. CA Cancer J Clin 68(1): 7-30, 2018.

4 Mortality and Causes of Death Collaborators: Global, regional, and national life expectancy, all-cause mortality, and causespecific mortality for 249 causes of death, 1980-2015: a systematic analysis for the Global Burden of Disease Study 2015. Lancet 388(9963): 1459-1544, 2016.

5 Marley AR and Nan H: Epidemiology of colorectal cancer. Int J Mol Epidemiol Genet 7(3): 105-114, 2016.

6 Maringe C, Walters S, Rachet B, Butler J, Fields T, Finan P, Maxwell R, Nedrebo B, Pahlman L, Sjovall A, Spigelman A, Engholm G, Gavin A, Gjerstorff ML, Hatcher J, Johannesen TB, Morris E, McGahan CE, Tracey E, Turner D, Richards MA and Coleman MP: Stage at diagnosis and colorectal cancer survival in six high-income countries: a population-based study of patients diagnosed during 2000-2007. Acta Oncol 52(5): 919-932, 2013.

7 Meert AP, Paesmans M, Martin B, Delmotte P, Berghmans T, Verdebout JM, Lafitte JJ, Mascaux C and Sculier JP: The role of microvessel density on the survival of patients with lung cancer: a systematic review of the literature with meta-analysis. Br J Cancer 87(7): 694-701, 2002.
8 Nakayama H, Enzan H, Miyazaki E, Kuroda N, Naruse K and Hiroi M: Differential expression of CD34 in normal colorectal tissue, peritumoral inflammatory tissue, and tumour stroma. J Clin Pathol 53(8): 626-629, 2000.

9 Lin CS, Ning H, Lin G and Lue TF: Is CD34 truly a negative marker for mesenchymal stromal cells? Cytotherapy 14(10): 1159-1163, 2012.

10 Nielsen JS and McNagny KM: Novel functions of the CD34 family. J Cell Sci 121(Pt22): 3683-3692, 2008.

11 Fina L, Molgaard HV, Robertson D, Bradley NJ, Monaghan P, Delia D, Sutherland DR, Baker MA and Greaves MF: Expression of the CD34 gene in vascular endothelial cells. Blood 75(12): 2417-2426, 1990.

12 Sidney LE, Branch MJ, Dunphy SE, Dua HS and Hopkinson A: Concise review: evidence for CD34 as a common marker for diverse progenitors. Stem Cells 32(6): 1380-1389, 2014.

13 Bing Z, Jian-ru Y, Yao-quan J and Shi-feng C: Evaluation of angiogenesis in non-small cell lung carcinoma by CD34 immunohistochemistry. Cell Biochem Biophys 70(1): 327-331, 2014.

14 Balac I, Jurisic V, Laban A, Randelovic T, Knezevic P, Pantic I and Dzodic R: The CD34-microvascular density in colorectal cancer patients. J BUON 17(1): 97-101, 2012.

15 Guset G, Costi S, Lazar E, Dema A, Cornianu M, Vernic C and Paiusan L: Expression of vascular endothelial growth factor (VEGF) and assessment of microvascular density with CD34 as prognostic markers for endometrial carcinoma. Rom J Morphol Embryol 51(4): 677-682, 2010.

16 Popiela TJ, Sikora J, Klimek M, Basta P, Niemiec T, Dobrogowski J, Kotlarz A, Rudnicka-Sosin L and Dutsch-Wicherek M: The analysis of CD34 antigen immunoreactivity level in invasive ductal breast cancer with respect to the presence of lymph node metastases. Neuro Endocrinol Lett 29(4): 443-446, 2008.

17 Kim HS, Kang HS, Messam CA, Min KW and Park CS: Comparative evaluation of angiogenesis in gastric adenocarcinoma by nestin and CD34. Appl Immunohistochem Mol Morphol 10(2): 121-127, 2002.

18 Nowak A, Grzegrzolka J, Paprocka M, Piotrowska A, Rys J, Matkowski R and Dziegiel P: Nestin-positive microvessel density is an independent prognostic factor in breast cancer. Int J Oncol 51(2): 668-676, 2017.

19 Nowak A, Grzegrzolka J, Kmiecik A, Piotrowska A, Matkowski $\mathrm{R}$ and Dziegiel P: Role of nestin expression in angiogenesis and breast cancer progression. Int J Oncol 52(2): 527-535, 2018.

20 Lendahl U, Zimmerman LB and McKay RD: CNS stem cells express a new class of intermediate filament protein. Cell 60(4): 585-595, 1990

21 Sejersen $\mathrm{T}$ and Lendahl $\mathrm{U}$ : Transient expression of the intermediate filament nestin during skeletal muscle development. J Cell Sci 106(Pt 4): 1291-1300, 1993.

22 Lardon J, Rooman I and Bouwens L: Nestin expression in pancreatic stellate cells and angiogenic endothelial cells. Histochem Cell Biol 117(6): 535-540, 2002.

23 Krupkova O Jr., Loja T, Zambo I and Veselska R: Nestin expression in human tumors and tumor cell lines. Neoplasma 57(4): 291-298, 2010.

24 Liang ZW, Wang Z, Chen H, Li C, Zhou T, Yang Z, Yang X, Yang Y, Gao G and Cai W: Nestin-mediated cytoskeletal remodeling in endothelial cells: novel mechanistic insight into VEGF-induced cell migration in angiogenesis. Am J Physiol Cell Physiol 308(5): C349-C358, 2015. 
25 Kobayashi H, Kosaka T, Mikami S, Miyazaki Y, Matsumoto K, Kikuchi E, Miyajima A, Kameyama K, Sato Y and Oya M: Vasohibin-1 as a novel microenvironmental biomarker for patient risk reclassification in low-risk prostate cancer. Oncotarget 9(12): 10203-10210, 2018.

26 Weidner N, Semple JP, Welch WR and Folkman J: Tumor angiogenesis and metastasis - correlation in invasive breast carcinoma. N Engl J Med 324(1): 1-8, 1991.

27 Algire G, Chalkley H, Legallais F and Park H: Vascular reactions of normal and malignant tissues in vivo. I. Vascular reactions of mice to wounds and to normal and neoplastic transplants. J Natl Cancer Inst 6: 73-85, 1945.

28 Folkman J: Tumor angiogenesis: therapeutic implications. N Engl J Med 285(21): 1182-1186, 1971.

29 Folkman J: What is the evidence that tumors are angiogenesis dependent? J Natl Cancer Inst 82(1): 4-6, 1990.

30 Paduch R: The role of lymphangiogenesis and angiogenesis in tumor metastasis. Cell Oncol (Dordr) 39(5): 397-410, 2016.

31 Wang Y, Yao X, Ge J, Hu F and Zhao Y: Can vascular endothelial growth factor and microvessel density be used as prognostic biomarkers for colorectal cancer? A systematic review and meta-analysis. Scientific World J 2014: 102736, 2014.

32 Rajaganeshan R, Jayne DG, Malik HZ, Scott N, Lodge JP, Toogood GJ and Prasad KR: Biological characteristics and behaviour of putatively curatively resected colorectal liver metastases. Eur J Surg Oncol 34(4): 439-444, 2008.

33 Cianchi F, Palomba A, Messerini L, Boddi V, Asirelli G, Perigli G, Bechi P, Taddei A, Pucciani F and Cortesini C: Tumor angiogenesis in lymph node-negative rectal cancer: correlation with clinicopathological parameters and prognosis. Ann Surg Oncol 9(1): 20-26, 2002.

34 Moreira LR, Schenka AA, Latuf-Filho P, Penna AL, Lima CS, Soares FA, Trevisan MA and Vassallo J: Immunohistochemical analysis of vascular density and area in colorectal carcinoma using different markers and comparison with clinicopathologic prognostic factors. Tumour Biol 32(3): 527-534, 2011.

35 Vermeulen PB, Van den Eynden GG, Huget P, Goovaerts G, Weyler J, Lardon F, Van ME, Hubens G and Dirix LY: Prospective study of intratumoral microvessel density, p53 expression and survival in colorectal cancer. Br J Cancer 79(2): 316-322, 1999.

36 Tanigawa N, Amaya H, Matsumura M, Lu C, Kitaoka A, Matsuyama $\mathrm{K}$ and Muraoka R: Tumor angiogenesis and mode of metastasis in patients with colorectal cancer. Cancer Res 57(6): 1043-1046, 1997.

37 Hasebe T, Sasaki S, Sugitoh M, Ono M, Saitoh N and Ochiai A: Proliferative activities of tumor stromal cells play important roles in tumor thickness and progression of T3 ulcerative-type colorectal cancer. Virchows Arch 442: 569-576, 2003.
38 Teranishi N, Naito Z, Ishiwata T, Tanaka N, Furukawa K, Seya T, Shinji S and Tajiri T: Identification of neovasculature using nestin in colorectal cancer. Int J Oncol 30: 593-603, 2007.

39 Li J, Wang R, Yang L, Wu Q, Wang Q, Nie Z, Yu Y, Ma J and Pan Q: Knockdown of nestin inhibits proliferation and migration of colorectal cancer cells. Int J Clin Exp Pathol 8: 6377-6386, 2015.

40 Matsuda $Y$, Hagio $M$ and Ishiwata T: Nestin: a novel angiogenesis marker and possible target for tumor angiogenesis. World J Gastroenterol 19: 42-48, 2013.

41 Uzzan B, Nicolas P, Cucherat M and Perret GY: Microvessel density as a prognostic factor in women with breast cancer: a systematic review of the literature and meta-analysis. Cancer Res 64: 2941-2955, 2005.

42 Sundov Z, Tomic S, Alfirevic S, Sundov A, Capkun V, Nincevic Z, Nincevic J, Kunac N, Kontic M, Poljak N and Druzijanic N: Prognostic value of MVD, LVD and vascular invasion in lymph node-negative colon cancer. Hepatogastroenterology 60: 432438, 2013.

43 Tomisaki S, Ohno S, Ichiyoshi Y, Kuwano H, Maehara Y and Sugimachi K: Microvessel quantification and its possible relation with liver metastasis in colorectal cancer. Cancer 77: 1722-1728, 1996.

44 Choi HJ, Hyun MS, Jung GJ, Kim SS and Hong SH: Tumor angiogenesis as a prognostic predictor in colorectal carcinoma with special reference to mode of metastasis and recurrence. Oncology 55: 575-581, 1998.

45 Asleh K, Won JR, Gao D, Voduc KD and Nielsen TO: Nestin expression in breast cancer: association with prognosis and subtype on 3641 cases with long-term follow-up. Breast Cancer Res Treat 168(1): 107-115, 2017.

46 Tabata K, Matsumoto K, Minami S, Ishii D, Nishi M, Fujita T, Saegusa M, Sato Y and Iwamura M: Nestin is an independent predictor of cancer-specific survival after radical cystectomy in patients with urothelial carcinoma of the bladder. PLoS One 9: e91548, 2014.

47 Liu F, Zhang Y, Lu M, Wang C, Li Q, Gao Y, Mu D, Cao Y, Li $\mathrm{M}$ and Meng $\mathrm{X}$ : Nestin servers as a promising prognostic biomarker in non-small cell lung cancer. Am J Transl Res 9: 1392-1401, 2017.
Received May 8, 2018

Revised June 2, 2018

Accepted June 4, 2018 